\title{
Solar STEP Organic Decomposition Plus Hydrogen: A Novel Approach to Efficient Degradation of Organic Pollutants Exemplified by Acrylonitrile
}

\author{
Dandan Yuan, Xiaoyan Shen, Lei Tian, Di Gu, Lingyue Zhu and Baohui Wang* \\ Institute of New Energy Chemistry and Environmental Science, College of Chemistry and Chemical Engineering, \\ Northeast Petroleum University, Daqing 163318 (PR China) \\ E-mail: Baohui Wang - wangbh@ nepu.edu.cn $\quad$ TEL: +8613359509696 $\quad$ Fax: +86-459-6503498
}

\begin{abstract}
The Solar Thermal Electrochemical Process has been adapted to an organic decomposition reaction for application in wastewater treatment plus hydrogen production. The theory and process are proposed and exemplified by efficient decomposition of acrylonitrile (AN) as a model compound of environmental pollutants. The results demonstrate thermodynamically that a decrease in the decomposition energy/electrolysis potential can be achieved with an increase in reaction temperature by solar heating, which also leads to improved reaction kinetics to sustain high rates of decomposition at low electrochemical overpotential. It is demonstrated experimentally that the STEP decomposition process of organic pollutants plus hydrogen production is performed with high efficiency for the removal of acrylonitrile by $21.6 \%$ at $25{ }^{\circ} \mathrm{C}, 34.5 \%$ at $40{ }^{\circ} \mathrm{C}$, and $56.3 \%$ at $75{ }^{\circ} \mathrm{C}$ using an applied current of $50 \mathrm{~mA}$. The process provides lower potential and higher efficiency compared with the conventional electrochemical oxidation by balancing and controlling the thermal and electrochemical components. Based on the results of the $\mathrm{CV}, \mathrm{GC}$ and experimental analysis, the pathways are proposed and explained for the thermo- and electrochemical decomposition of acrylonitrile using the solar STEP process. Due to the solar thermo- and electrochemical combination, this pathway is shifted from the indirect reaction of the conventional electrooxidation involving several intermediates to a direct pathway with rapid rate and high efficiency with synergetic production of hydrogen.
\end{abstract}

Key words: Solar; STEP process; Organic decomposition; Hydrogen; Electrochemical oxidation; Acrylonitrile

\section{Introduction}

With the shortage of non-renewable energy sources such as oil, gas and coal, an exploration of renewable energy has become a global challenge. Solar energy has been considered as a boundless source of green, sustainable, and safe energy ${ }^{[1-3]}$. The utilization of solar energy has been rapidly developed as a priority sector for the production of heat and 
electricity in the past years ${ }^{[4,5]}$. Moreover, the other applications are emerging in the recent years ${ }^{[6-11]}$. In our recent studies, the Solar Thermal Electrochemical Process (STEP) has been investigated for a number of chemical processes, including STEP iron, STEP $\mathrm{CO}_{2}$ capture and fuel, STEP cement ${ }^{[12-15]}$ and most recently STEP ammonia ${ }^{[16]}$. These processes successfully utilize solar energy without input of any other forms of energy. In terms of classical chemistry, we also successfully employed the STEP process for the preparation of benzoic acid from toluene ${ }^{[17,18]}$.

Another important application is organic decomposition, the conversion of an organic compound into elements or simpler compounds, which can be desirable or undersirable depending on the situation. Organic decomposition is sometimes defined as a major chemical reaction in chemistry, which is often an undesired/desired reaction. There are three broad types of decomposition reactions: thermal, electrolyzing and photochemical reactions. Chemical stability is eventually limited with exposure to extreme environmental conditions, such as heat, radiation, humidity or the acidity of a solvent, however, the details of the resulting decomposition processes are generally not well defined, as a molecule may break up into a host of smaller fragments. The generalized reaction for chemical decomposition is: $\mathrm{AB} \rightarrow \mathrm{A}+\mathrm{B}$ with a specific example being the electrolysis of water to gaseous hydrogen and oxygen: $2 \mathrm{H}_{2} \mathrm{O}(\mathrm{l}) \rightarrow 2 \mathrm{H}_{2}(\mathrm{~g})+\mathrm{O}_{2}(\mathrm{~g})$. For a specific organic decomposition, the compound is broken down to $\mathrm{CO}_{2}$ and the other small molecules.

In recent years, there has been an increasing interest in finding innovative solutions for the efficient removal of organic pollutants from wastewater ${ }^{[19-24]}$. Generally, wastewater treatment to remove organic pollutants involves chemical oxidation methods with ozone or chlorine dioxide ${ }^{[25,26]}$. However, depending on the nature of the pollutants, these methods are not always feasible due to the high cost of $\mathrm{O}_{3}(\mathrm{~g})$ and $\mathrm{ClO}_{2}(\mathrm{~g})$, as well as storage issues of these compounds, and sometimes such treatment may be impossible. This paper reports the investigation of the STEP organic decomposition for efficient degradation of organic pollutants as an innovative use of solar energy to benefit the environment plus the production of solar hydrogen.

As well known, increasing the temperature lowers the free energy requirements for processes with endothermic electrolysis potentials. The STEP uses solar energy to promote an otherwise energetically forbidden pathway of charge transfer and to improve reaction kinetics. The process integrates concepts of solid state physics, insolation (solar illumination) and high temperature electrochemical energy conversion. The result is a synergy, making use of the full spectrum of sunlight, allowing capture of a greater fraction of solar energy. The STEP is intrinsically more efficient than other solar energy conversion processes, as it utilizes not only visible sunlight to drive photovoltaic cells (PVs), as well as the previously destructive (due to PV thermal degradation) thermal component of sunlight, for the electrolytic formation of chemicals. By increasing the temperature, the electrochemical potential, $E_{\text {redox }}$, to drive a variety of electrochemical syntheses is lowered, and the extent of this lowering may be tuned by choosing the constituents and temperature of the electrolysis.

In this work, the STEP approach is applied to the decomposition of acrylonitrile with synergetic production of hydrogen, which is heavily used in industry for production of nitriles, such as benzonitrile herbicides, as the precursor for the synthesis of polyacrylonitrile plastics, and as an organic solvent. For example, acrylonitrile is the primary component in acrylonitrile butadiene styrene (ABS) resin, and is a precursor of acrylic fibers. The $\mathrm{CN}$ triple bond makes many nitriles 
quite toxic and generally non-biodegradable, and acrylonitrile ${ }^{[27]}$ has been proved to be carcinogenic in rodents ${ }^{[28]}$. Indiscriminate discharge of improperly treated nitrile wastes into natural bodies of water can cause serious problems and severely impact aquatic ecology [29]. Diverse treatment methods for acrylonitrile include incineration ${ }^{[30]}$, pressure hydrolysis ${ }^{[31]}$ and catalytic wet oxidation ${ }^{[32]}$, all of which have flaws and are not environmentally friendly. It is high time to seek a novel approach. In this study, acrylonitrile is used as a model compound to demonstrate STEP decomposition plus hydrogen production. The efficient decomposition of acrylonitrile to form primarily carbon dioxide is fully driven by solar energy without the input of any other forms of energy.

\section{Experimental Section}

\subsection{Chemicals and Materials}

All aqueous solutions were prepared with deionized water. Sources of key reagents include: acrylonitrile $\left(\mathrm{C}_{3} \mathrm{H}_{3} \mathrm{~N}\right.$, Zibo Weighing Chemical Co., LTD, 99.5\%), acetonitrile $\left(\mathrm{C}_{2} \mathrm{H}_{3} \mathrm{~N}\right.$, Yuwang Industrial Co., Ltd., 99.9\%), acrylic acid $\left(\mathrm{C}_{3} \mathrm{H}_{4} \mathrm{O}_{2}\right.$, Damao Chemical, 99.5\%), methyl alcohol $\left(\mathrm{CH}_{3} \mathrm{OH}\right.$, Kermel Chemical, Ltd., 99.5\%), formaldehyde (HCHO, Qidashan Fine Chemical, $99.5 \%)$, and sodium sulfate $\left(\mathrm{Na}_{2} \mathrm{SO}_{4}\right.$, Tak Sun Chemical).

\subsection{High-temperature Cyclic Voltammetry Measurements}

High-temperature cyclic voltammetry (CV) experiments were performed with an Autolab NOVA electrochemical workstation at a sweep rate of $100 \mathrm{mV} / \mathrm{s}$ with a conventional three-electrode electrochemical cell made of cylindrical glass. The rubber stopper lid was designed to accommodate the working, counter and reference electrodes, which were arranged as an equilateral triangle (side length of $2 \mathrm{~cm}$ ) in the aqueous solution of acrylonitrile ( $200 \mathrm{ppm} \mathrm{in} 5 \mathrm{~g} / \mathrm{L} \mathrm{Na}_{2} \mathrm{SO}_{4}$ as an electrolyte) in the cylindrical vessel. The working electrodes were used as described in the next section. The counter electrode was a platinum foil $(10 \mathrm{~mm} \times 10 \mathrm{~mm})$.The reference electrode was a saturated calomel electrode (SCE) with a Luggin capillary that can be kept very close to the working electrode to minimize the iR drop.

\subsection{Solar STEP Organic Decomposition Experiments}

The main sections of the solar STEP organic decomposition performed in the experiment are shown in the Scheme 2. The experiments are exhibited in the following sections in details. Other aspects have been described previously ${ }^{[17,18]}$.

\subsubsection{Configuration of the Thermo-Electrochemical Reactor}

A two-electrode and coupled thermo-electrochemical cell (reactor), equipped with dimensionally stable anodes (DSA, $\left.\mathrm{Ti} /\left(\mathrm{IrO}_{2} \& \mathrm{Ta}_{2} \mathrm{O}_{5}\right), 20 \mathrm{~mm} \times 20 \mathrm{~mm}\right)$ and a high purity of platinum foil $(10 \mathrm{~mm} \times 10 \mathrm{~mm})$, was employed for the STEP organic decomposition of acrylonitrile experiments. The aqueous solution contained $200 \mathrm{ppm}$ acrylonitrile in $5 \mathrm{~g} / \mathrm{L}$ $\mathrm{Na}_{2} \mathrm{SO}_{4}$ was utilized as an electrolyte. The potential, current, temperature, time and the other conditions were applied and 
adjusted by the solar photothermal unit and solar photoelectric units which were detailed in the following subsection.

\subsubsection{Solar Photothermal Unit}

A solar concentrator was used to regulate the temperature of the thermo-electrochemical reactor. Axially symmetric, parabolic-cross-section reflectors were used to collect energy from parallel incident light and bring it to a single focal point at high temperature (Max. Temp.500 ${ }^{\circ} \mathrm{C}$ ). A $1.5 \mathrm{~m}$ diameter, parabolic solar concentrator was used in the experiments for high magnification and was equipped with 2-dimensional tracking reflector control systems to maintain the solar focus. Wastewater is produced by filling a reactor at focus point of solar concentrator at temperatures reaching RT $-500{ }^{\circ} \mathrm{C}$ tuned by the tracking control system.

\subsubsection{Solar Photoelectric Unit}

The solar photoelectric unit consisted of silicon-based photovoltaic modules plus a lithium storage battery to convert solar energy into electrical energy. The solar panels could provide the desired power for electrolysis by simultaneous fine-tuning of the voltage transformer and current transformer. A polycrystalline silicon solar module (3 W/18 V, VUAVA, China), consisting of thirty-six pcs $(2 \times 18)$ dimension: $1.0 \mathrm{~cm} \times 7.8 \mathrm{~cm}$ cells, was used for the solar photoelectric unit. The modules provided the following: open circuit voltage $\left(\mathrm{V}_{\mathrm{oc}}\right): 21.8 \mathrm{~V}$; short circuit current $\left(\mathrm{I}_{\mathrm{sc}}\right)$ : 0.2 A; maximum power voltage $(\mathrm{Vmp}): 18 \mathrm{~V}$; maximum power current $\left(\mathrm{I}_{\mathrm{mp}}\right): 0.17 \mathrm{~A}$; maximum power $\left(\mathrm{P}_{\max }\right): 3 \mathrm{~W}$, and a solar efficiency of $18 \%$ under a standard AM (air mass) 1.5 insolation, with the temperature of $25^{\circ} \mathrm{C}$. The desired cell potentials were applied by a voltage regulator.

\subsection{Analysis of the STEP Organic Decomposition Products}

The product analysis was conducted by a gas chromatograph (Shimadzu 14C, Japan) equipped with a flame ionization detector. The aqueous solution contained 1000 ppm acrylonitrile in $10 \mathrm{~g} / \mathrm{L} \mathrm{Na} \mathrm{SO}_{4}$ was used as an electrolyte. The gas chromatographic separation was performed on a HP-5 $(30 \mathrm{~m} \times 0.32 \mathrm{~mm}$, ID $\times 0.25 \mu \mathrm{m}$, USA) column at a constant nitrogen flow of $2 \mathrm{~mL} / \mathrm{min}$. The column started at $50{ }^{\circ} \mathrm{C}$ at the starting stage and then increased at a rate of $5{ }^{\circ} \mathrm{C} / \mathrm{min}$ to $220{ }^{\circ} \mathrm{C}$ final held $20 \mathrm{~min}$. The evolved gases were detected by a natural gas chromatograph (Shimadzu 14C, Japan). The rate of acrylonitrile decomposition was calculated by dividing the concentration of the decomposited acrylonitrile by the initial concentration.

\section{Results and Discussion}

\subsection{Overview of STEP Organic Decomposition for Environmental Chemistry}

An overview of the STEP organic decomposition process is illustrated in Scheme 1. The anodic degradation of acrylonitrile is accompanied by the simultaneous generation of hydrogen at the cathode. 


\subsection{Mode of the STEP Organic Decomposition for Environmental Chemistry}

The practical system and mode of the STEP organic decomposition is schematically presented in Scheme 2. The STEP process consists of photothermal, photoelectric and electrochemical units to make use of the full spectrum of sunlight and to capture more solar energy for the thermo- and electrochemical reaction. The device provides the potential required to drive endothermic electrolysis changes, whose potential decreases with the increasing temperature [33-35], by a combination of thermochemistry with electrochemistry fully driven by the sun.

\subsection{Theory of the STEP Organic Decomposition for Environmental Chemistry}

The STEP process is more efficient at higher temperatures, because of the lower electrolysis potential. In the decomposition process, acrylonitrile molecules are discharged on the anode ${ }^{[36,37]}$ to form intermediates which are then completely oxidized to $\mathrm{CO}_{2}$ and nitrate, while $\mathrm{H}_{2}$ is generated on the cathode. The corresponding half-reactions are :

Anode, electrochemical oxidation of acrylonitrile to $\mathrm{CO}_{2}$ :

$$
\mathrm{CH}_{2}=\mathrm{CH}-\mathrm{CN}(\mathrm{l})+9 \mathrm{H}_{2} \mathrm{O}(\mathrm{l}) \rightarrow 3 \mathrm{CO}_{2}(\mathrm{~g})+\mathrm{NO}_{3}^{-}+21 \mathrm{H}^{+}(\mathrm{l})+20 \mathrm{e}^{-}
$$

Cathode, hydrogen evolution (Plus):

$$
20 \mathrm{H}^{+}(\mathrm{l})+20 \mathrm{e}^{-} \rightarrow 10 \mathrm{H}_{2}(g)
$$

Full cell reaction:

$$
\mathrm{CH}_{2}=\mathrm{CH}-\mathrm{CN}(\mathrm{l})+9 \mathrm{H}_{2} \mathrm{O}(\mathrm{l}) \rightarrow 3 \mathrm{CO}_{2}(\mathrm{~g})+\mathrm{HNO}_{3}+10 \mathrm{H}_{2}(\mathrm{~g})
$$

As seen from the full cell reaction, the green fuel $\mathrm{H}_{2}$ is generated in the STEP process simultaneously with the degradation of acrylonitrile. $\triangle H^{\mathrm{o}}$ and $\triangle G^{\mathrm{o}}$ of the cell reaction can be computed from the thermodynamic data at different temperatures and used to calculate the theoretical electrode potential. This thermoneutral potential, $E_{T}^{o}$, is given by:

$$
E_{T}^{\mathrm{o}}=\triangle H^{\mathrm{o}}\left(T=T_{\mathrm{STEP}}\right) / \mathrm{n} F
$$

Thermoneutral potentials for acrylonitrile oxidation were calculated from Equation 3 and 4 for temperatures from $20{ }^{\circ} \mathrm{C}$ to $100{ }^{\circ} \mathrm{C}$ and plotted in Fig. 1. The curve shows that the oxidation potential of acrylonitrile dramatically decreases from $0.642 \mathrm{~V}\left(25^{\circ} \mathrm{C}\right)$ to $0.569 \mathrm{~V}\left(75^{\circ} \mathrm{C}\right)$, and all other indicated electrolysis potentials, including that of water for the hydrogen, decrease with increasing temperature.

\subsection{Experiments of STEP Organic Decomposition for Environmental Chemistry}

\subsubsection{High-temperature cyclic voltammetry of acrylonitrile oxidation}

The conventional electrolysis of dissolved organic pollutants has been previously investigated at or near room temperature in aqueous media, where the endothermic processes are constrained by high electrolysis overpotentials, low 
electrolysis rates and low electrolysis efficiencies. Although maintaining a high temperature can be very costly, the sun can easily serve this task. The high temperature activates the reactants or leads to alternate chemical reactions. It is necessary that the thermochemistry is perfectly combined with the electrochemistry for the efficient utilization of solar energy. The coupling effect can be well displayed by using measurements of high-temperature cyclic voltammetry.

Fig. 2 presents the high-temperature cyclic voltammogram of aqueous acrylonitrile at a series of temperatures. Two anodic peaks (A-I and A-II) of acrylonitrile oxidation occur as the potential is scanned in the positive direction, and they are both less than the onset potential of the oxygen evolution $\left(\geqslant 1.0 \mathrm{~V}\right.$ vs SCE $\left(\mathrm{H}_{2} \mathrm{O}(\mathrm{l}) \rightarrow \mathrm{H}_{2}(\mathrm{~g})+1 / 2 \mathrm{O}_{2}(\mathrm{~g})+\mathrm{e}^{-}\right)$. This indicates that the potentials of acrylonitrile oxidation are less than that for oxidation of water, thus favoring efficient electrooxidation. The two anodic peaks are attributed to acidification (A-I, acrylonitrile to acrylic acid) and decarboxylation (A-II, acrylonitrile / intermediates to carbon dioxide as shown in the below mechanistic analysis, preferably acrylonitrile is converted directly to carbon dioxide at high temperature).

Fig. 3 demonstrates the temperature variation of the anodic oxidation peak potential and current (A-II). It is obvious that the anodic oxidation peak potential is sharply lowered while the peak current increases with increasing temperature. This effect is significant for the A-II peak, which shows a large potential drop of $0.32 \mathrm{~V}(1.12 \mathrm{~V}$ to $0.80 \mathrm{~V})$ from $25{ }^{\circ} \mathrm{C}$ to 75 ${ }^{\circ} \mathrm{C}$. According to the mechanistic analysis described below, the decarboxylation (A-II, intermediates to carbon dioxide) is a hard step in acrylonitrile decomposition. An aim is to decrease the potential and increase the current. The results show that thermal energy supplied in the STEP process can decrease the necessary potential/energy, and the combination of thermochemistry with electrochemistry changes the mechanism and pathway. Thus, an indirect multistep reaction is shifted to a one-step process for the decomposition of acrylonitrile.

Fig. 4 shows the measured anodic (top) and cathodic (bottom) currents for the cyclic voltammetry of water electrolysis at different temperatures. The substantial growth in current from $25{ }^{\circ} \mathrm{C}$ to $75{ }^{\circ} \mathrm{C}$ indicates that $\mathrm{H}_{2} \mathrm{O}$ splitting kinetics becomes more favorable with increasing temperature ${ }^{[38,39]}$. The temperature effect is also observed in the curves. The results are consistent with the conclusion drawn from Fig. 1. In other words, $\mathrm{H}_{2} \mathrm{O}$ splitting can generate more $\bullet \mathrm{OH}$ to oxidize acrylonitrile at a higher temperature and facilitate the degradation of acrylonitrile.

\subsubsection{Experimental STEP Acrylonitrile Decomposition}

Following the results of the thermodynamic calculation and CV measurements, the dependence of temperature on applied potential was tested by employing outdoor mode STEP acrylonitrile decomposition at constant current. A rapid drop in the applied potential was observed with increasing temperature, as shown in Fig. 5. Thus, the thermal effect occurs in the outdoor experiment of the STEP acrylonitrile decomposition.

The decomposition rates at the constant electrolysis current and fixed time interval (50 $\mathrm{mA}$ and 1hour) as varying temperature, are shown in the Fig. 6. It is remarkable observation that the thermochemical effect plays an important role in the decomposition.

For testing and verifying the role of the thermo-electrochemical combination characterized by the STEP acrylonitrile decomposition, the fixed volume of solution experiments was performed under a constant temperature and current (25, 
40, 60, $75^{\circ} \mathrm{C}, 50 \mathrm{~mA}, 1$ hour). The dependence of decomposition rate on temperature, plotted in Fig. 6, shows that in the $50 \mathrm{~mA}$ system, temperature at or above $75^{\circ} \mathrm{C}$ is conducive to a substantial electrochemical oxidative decomposition of acrylonitrile. The oxidation efficiency increases from $21.6 \%$ to $56.3 \%$ by lifting the temperature with solar heating from 25 to $75{ }^{\circ} \mathrm{C}$. This point indicates that high temperature is conducive to rapid decomposition. As temperature raises the energy of reactant molecules, the change in mechanistic pathway is more electrochemically feasible. The reaction rate is enhanced by increasing temperature, as shown in Fig. 7. As explained below, a rapid STEP process is achieved by the thermochemical effect.

At low temperatures, the oxidation of acrylonitrile is incomplete, and water hydrolysis is competitive reaction. The decomposition is enhanced with increasing temperature, because only a small portion of the current is directed to the competing water oxidation process. This indicates that the complete oxidation of acrylonitrile to $\mathrm{CO}_{2}$ is more likely to occur at high temperature, in agreement with the CV plots in Fig. 3. The STEP process can be carried out more efficiently at higher temperature with lower required electrolysis potential.

\subsection{Mechanism and Pathway STEP Decomposition of Acrylonitrile}

On the basis of the experimental results, a simplified reaction mechanism for thermo- and electrochemical decomposition of acrylonitrile driven by the solar STEP process is discussed in this section. For fully understanding the mechanism and pathway, the mechanism of the conventional electrochemical oxidation of acrylonitrile must be reviewed. This mechanism involves coupling of the electron transfer reaction with a dissociative chemisorption step involving protoncoupled electron transfer and the movement of electrons between an electrode and substrate. Acidification of acrylonitrile to acrylic acid (pathway I) occurs quickly over the entire temperature range. The much slower process is a decarboxylation of acrylonitrile to carbon dioxide (pathway II). The cyano group is strong electron withdrawing. As shown in Step 1 below, the $\alpha-\mathrm{C}$ is negative while $\beta-\mathrm{C}$ is positive, leading to facile addition of water across the $\mathrm{C}=\mathrm{C}$ bond, as shown in Step 2. Subsequently, formation of $\mathrm{CH}_{3}-\mathrm{CN}$ and $\mathrm{HCHO}$ occurs with intramolecular transfer of hydrogen and the cleavage of the $\mathrm{C}=\mathrm{C}$ bond (Step 3$)$.

Pathway I:

Acidification from acrylonitrile to acrylic acid:

$\mathrm{CH}_{2}=\mathrm{CH}-\mathrm{CN} \rightarrow \mathrm{CH}_{2}=\mathrm{CH}-\mathrm{COOH}$

Pathway II:

Decarboxylation from acrylonitrile/intermediates to carbon dioxide

$\mathrm{CH}_{2}=\mathrm{CH}-\mathrm{CN}$ (or intermediates such as $\mathrm{RCOOH}, \mathrm{RCHO}$ and $\mathrm{ROH}$ ) $\rightarrow \mathrm{CO}_{2}$

Via the following steps:

Step 1: Electro transfer<smiles></smiles> 
Step 2: Addition of water

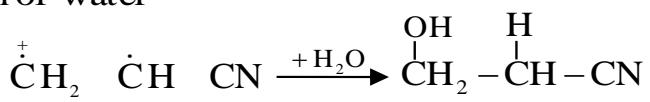

Step 3: Hydrogen transfer \& Scission<smiles>C[C@H](CCO)[C@H](C#N)CC[N+]=C[O-]</smiles>

To elucidate the mechanism for thermo- and electrochemical decomposition of acrylonitrile, the initial reactants and intermediates were tracked by gas chromatography during acrylonitrile decomposition at low and high temperature (25 and $75^{\circ} \mathrm{C}$ ) as shown in Fig. 8.

In the chromatogram for the low temperature reaction (top) there are many peaks, corresponding to the initial reactant (acrylonitrile, $\mathrm{AN}$ ) and intermediates (acrylic acid, $\mathrm{AA} ; \mathrm{CH}_{3} \mathrm{CN} ; \mathrm{CH}_{3} \mathrm{OH} ; \mathrm{HCHO}$ etc.), while the chromatogram for the high-temperature reaction shows only the initial acrylonitrile and a small concetration of $\mathrm{CH}_{3} \mathrm{CN}$.

The changes in the concentrations of the initial reactant (acrylonitrile) and intermediate (acetonitrile) were monitored throughout the decomposition as shown in Fig. 9. It is clear that the low- and high-temperature decompositions follow different mechanisms and pathways. The concentration of acrylonitrile drops sharply at high-temperature, with the appearance and slow conversion of acetonitrile. For the low-temperature situation, the concentration of acrylonitrile drops slowly with no appearance of acetonitrile until the 2-hrs point, indicating that the intermediate is acrylic acid, as shown in Fig. 8.

The combined results of the CV, GC and mechanistic analysis indicate that the thermo- and electrochemical pathways in the solar STEP process are as follows:

Pathway I at low temperature:

$\mathrm{CH}_{2}=\mathrm{CH}-\mathrm{CN} \rightarrow \mathrm{CH}_{2}=\mathrm{CH}-\mathrm{COOH} \rightarrow \mathrm{CH}_{3} \mathrm{CN} \rightarrow \mathrm{CH}_{3} \mathrm{OH} \rightarrow \mathrm{HCHO} \rightarrow \mathrm{HCOOH} \rightarrow \mathrm{CO}_{2}$

with more intermediates by the indirect reaction.

Pathway II at high temperature:

$\mathrm{CH}_{2}=\mathrm{CH}-\mathrm{CN} \rightarrow \mathrm{CH}_{3} \mathrm{CN} \rightarrow \mathrm{CO}_{2}$

with fewer intermediates by this direct reaction.

The schematic mechanisms and pathways are shown in Scheme 3.

Due to the synergy of the solar thermo- and electrochemical decomposition, these mechanisms and pathways are different in comparison with the conventional electrooxidation, resulting from both activation of the initial reactant and change to a direct pathway. As a result, the rate of acrylonitrile decomposition is increased while the efficiency is enhanced.

\section{Conclusions}

With the aim of the efficient solar utilization and sustainable wastewater treatment with the synergetic production of solar fuel, the solar-mediated STEP process has been extended to the novel STEP organic decomposition for wastewater 
treatment plus hydrogen production. As exemplified by acrylonitrile for a model compound of environmental pollutants, the theoretical calculation and experiments of the STEP acrylonitrile decomposition were presented to demonstrate a decrease in the decomposition energy / potential with an increase in the solar heat, and high efficiency and fast rate of the decomposition plus hydrogen production with the combination of thermochemical and electrochemical effect, which also improves the kinetics of the process. The mechanism and pathways were schematically proposed and discussed for the thermo- and electrochemical decomposition of acrylonitrile driven by the solar STEP process in the basis of the data of the $\mathrm{CV}, \mathrm{GC}$ and mechanistic analysis. The pathway was proved to be a switch of the indirect reaction followed in the conventional electrooxidation to the direct route characterized by rapid rate and high efficiency of acrylonitrile decomposition plus hydrogen production. This STEP organic decomposition, fully driven with solar energy to electric and heat energy, and without an input of other energy, serves as a green efficient and sustainable process for application of the decomposition for organic pollutants in wastewater with the synergistic production of hydrogen.

\section{Acknowledgements}

The research is financially supported by National Science Foundation of China (No. 21376049) and Innovative Team of Science and Technology in Heilongjiang Higher Education Institutes (No. 2013TD004). For the technical aids of the STEP theory and process we are grateful to Department of Chemistry, George Washington University, where one of the authors (BW) joined the partial works.

\section{Notes and references}

[1] V. Turanjanin, V. Bakić, M. Jovanović, et al. Fossil fuels substitution by the solar energy utilization for the hot water production in the heating plant "Cerak" in Belgrade. International Journal of Hydrogen Energy 2009; 34(16) : 7075-7080. doi:10.1016/j.ijhydene.2008.11.005

[2] H. Ozcan, I. Dincer. Energy and exergy analyses of a solar driven $\mathrm{Mg}-\mathrm{Cl}$ hybrid thermochemical cycle for co-production of power and hydrogen. International Journal of Hydrogen Energy 2014; 39(28) : 15330-15341. doi:10.1016/j.ijhydene.2014.07.089

[3] J. Nowotny, T. Bak, D. Chu, et al. Sustainable practices: Solar hydrogen fuel and education program on sustainable energy systems. International Journal of Hydrogen Energy 2014; 39(9) : 4151-4157. doi:10.1016/j.ijhydene.2013.12.114

[4] N.A. Kelly. The coupling factor: A new metric for determining and controlling the efficiency of solar photovoltaic power utilization. International Journal of Hydrogen Energy 2013; 38(5) : 2079-2094. doi:10.1016/j.ijhydene.2012.11.105

[5] O. Deveci, C. Kasnakoğlu. Performance improvement of a photovoltaic system using a controller redesign based on numerical modeling. International Journal of Hydrogen Energy 2016; 41(29) : 12634-12649. doi:10.1016/j.ijhydene.2016.05.149 
[6] C. Belabed, N. Haine, Z. Benabdelghani, et al. Photocatalytic Hydrogen Evolution on The Hetero-system Polypyrrol/ $\mathrm{TiO}_{2}$ Under Visible Light. International Journal of Hydrogen Energy 2014; 39(31) : 17533-17539. doi:10.1016/j.ijhydene.2014.08.107

[7] H. Zhang, W. Zhou, Y. Du, et al. Enhanced Electrocatalytic Performance for Methanol Oxidation on Pt-TiO $2 /$ ITO $^{2}$ Electrode Under UV Illumination. International Journal of Hydrogen Energy 2010; 35(24) : 13290-13297. doi:10.1016/j.ijhydene.2010.09.025

[8] C. Wang, R. Yue, H. Wang, et al. Dendritic Ag@Pt Coreeshell Catalyst Modified With Reduced Graphene Oxide and Titanium Dioxide: Fabrication, Characterization, and Its Photo-electrocatalytic Performance. International Journal of Hydrogen Energy 2014; 39(11) : 5764-5771. doi:10.1016/j.ijhydene.2014.01.192

[9] C. Zhai, M. Zhu, D. Bin, et al. Visible-Light-Assisted Electrocatalytic Oxidation of Methanol Using Reduced Graphene Oxide Modified Pt Nanoflowers- $\mathrm{TiO}_{2}$ Nanotube Arrays. ACS Applied Materials \& Interfaces 2014; 6(20) : 17753-17761. doi:10.1021/am504263e

[10] M. Zhu, Y. Lu, Y. Du, et al. Photocatalytic hydrogen evolution without an electron mediator using a porphyrin-pyrene conjugate functionalized Pt nanocomposite as a photocatalyst. International Journal of Hydrogen Energy 2011; 36(7) : 4298-4304. doi:10.1016/j.ijhydene.2011.01.007

[11] H. Zhang, W. Zhou, Y. Du. Enhanced electrocatalytic performance for methanol oxidation on Pt-TiO $/$ /ITO electrode under UV illumination. International Journal of Hydrogen Energy 2010; 35(24) : 13290-13297. doi:10.1016/j.ijhydene.2010.09.025

[12] S. Licht, B. Wang, H. Wu. STEP-A solar chemical process to end anthropogenic global warming. II: Experimental Results. The Journal of Physical Chemistry C 2011; 115(23) : 11803-11821. doi:10.1021/jp111781a

[13] S. Licht, B. Cui, B. Wang. STEP carbon capture-the barium advantage. Journal of $\mathrm{CO}_{2}$ Utilization $2013 ; 2$ : 58-63. doi:10.1016/j.jcou.2013.03.006

[14] S. Licht. Solar water splitting to generate hydrogen fuel-A photothermal electrochemical analysis. International Journal of Hydrogen Energy 2005; 30(5) : 459-470. doi:10.1016/j.ijhydene.2004.04.015

[15] S. Licht, H. Wu, C. Hettige. STEP cement: Solar Thermal Electrochemical Production of $\mathrm{CaO}$ without $\mathrm{CO}_{2}$ emission. Chemical Communications 2012; 48 : 6019-6021. doi: 10.1039/c2cc31341c

[16] S. Licht, B. Cui, B. Wang, et al. Ammonia synthesis by $\mathrm{N}_{2}$ and steam electrolysis in molten hydroxide suspensions of nanoscale $\mathrm{Fe}_{2} \mathrm{O}_{3}$. Science 2014; 345(6197) : 637-640. doi:10.1126/science.1254234

[17] Y. Zhu, B. Wang, H. Wang, et al. Towards efficient solar STEP synthesis of benzoic acid: Role of graphite electrode. Solar Energy 2015; 113 : 303-312. doi: 10.1016/j.solener.2015.01.009

[18] Y. Zhu, B. Wang, X. Liu, et al. STEP organic synthesis: an efficient solar, electrochemical process for the synthesis of benzoic acid. Green Chemistry 2014; 16 : 4758-4766. doi:10.1039/c4gc01448k

[19] G. Kim, E.T. Igunnu, G.Z. Chen. A sunlight assisted dual purpose photoelectrochemical cell for low voltage removal of heavy metals and organic pollutants in wastewater. Chemical Engineering Journal 2014; 244 : 411-421.doi:10.1016/j.cej.2014.01.090 
[20] M.J.M. Vidales, C. Sáez , J.F. Pérez. Irradiation-assisted electrochemical processes for the removal of persistent organic pollutants from wastewater. Journal of Applied Electrochemistry 2015; 45(7) : 799-808. doi: $10.1007 / \mathrm{s} 10800-015-0825-0$

[21] D.M. Araújo, P. Cañizares, C.A. Martínez-Huitle. Electrochemical conversion/combustion of a model organic pollutant on BDD anode: Role of $\mathrm{sp}^{3} / \mathrm{sp}^{2}$ ratio. Electrochemistry Communications 2014; 47 : 37-40. doi:10.1016/j.elecom.2014.07.017

[22] C. Leung, Y. Chen, H. Yu, et al. Electro- and Photocatalytic Hydrogen Generation in Acetonitrile and Aqueous Solutions by a Cobalt Macrocyclic Schiff-base Complex. International Journal of Hydrogen Energy 2011; 36(18) : 11640-11645. doi:10.1016/j.ijhydene.2011.06.062

[23] D. Li, Q. Zhu, C. Han, et al. Photocatalytic degradation of recalcitrant organic pollutants in water using a novel cylindrical multi-column photoreactor packed with $\mathrm{TiO}_{2}$-coated silica gel beads. Journal of Hazardous Materials 2015; 285 : 398-408. doi:10.1016/j.jhazmat.2014.12.024

[24] S. Murgolo, F. Petronella, R. Ciannarella. UV and solar-based photocatalytic degradation of organic pollutants by nano-sized $\quad \mathrm{TiO}_{2}$ grown on carbon nanotubes. Catalysis $\quad$ Today $2015 ; \quad 240 \quad: \quad 114-124$ doi:10.1016/j.cattod.2014.04.021

[25] S. Navalon, M. Alvaro, H. Garcia. Reaction of chlorine dioxide with emergent water pollutants: Product study of the reaction of three $\beta$-lactam antibiotics with $\mathrm{ClO}_{2}$. Water Research 2008; 42(8-9) : $1935-1942$. doi:10.1016/j.watres.2007.11.023

[26] J. Xiao, Y. Xie, F. Nawaz, et al. Dramatic coupling of visible light with ozone on honeycomb-like porous g- $_{3} \mathrm{~N}_{4}$ towards superior oxidation of water pollutants. Applied Catalysis B: Environmental 2016; 83 : 417-425. doi:10.1016/j.apcatb.2015.11.010

[27] J. Zhang, G.E. Pierce. Laboratory-scale biofiltration of acrylonitrile by rhodochrous DAP 96622 in a trickling bed bioreactor. Industrial Microbiology\&Biotechnology 2009; 36(7) : 971-979. doi:10.1007/s10295-009-0576-1

[28] L.T. Haber, J. Patterson. Report of an independent peer review of an acrylonitrile risk assessment. Hum Exp Toxicol 2005; 24 : 587-527. doi:10.1191/0960327105ht552oa

[29] J. Cheng, P. Jandik. Electroactivity of nitriles on platinum electrodes and its use in chromatographic detection. Electrochemistry Communications 2009; 11(8) : 1615-1617. doi:10.1016/j.elecom.2009.06.010

[30] C. Lu, M. Lin, J. Lin. Removal of acrylonitrile vapor from waste gases by a trickle-bed air biofilter. Bioresource Technology 2000; 75(1) : 35-41. doi:10.1016/S0960-8524(00)00029-8

[31] J.C. Lee, D.L. Trimm, M.S. Wainwright, et al. Metal-support effects in copper catalysts for the liquid phase hydrolysis of acrylonitrile. Applied Catalysis 1990; 60(1) : 173-179. doi:10.1016/S0166-9834(00)82180-6

[32] W.P. Zhu, Y.J Bin, Z.H. Li, et al. Application of catalytic wet air oxidation for the treatment of H-acid manufacturing process wastewater. Water Research 2002; 36(8) : 1947-1954. doi:10.1016/S0043-1354(01)00419-5

[33] B. Wang, Y. Hu, H. Wu, et al. Solar Driven Thermal Electrochemical Process (STEP) Wastewater Treatment with Synergistic Production of Hydrogen. ECS Electrochemistry Letters 2013; 2 (9) : H34-H36. 
doi:10.1149/2.008309eel

[34] S. Licht, B. Wang, S. Ghosh, H. Ayub, et al. A New Solar Carbon Capture Process: Solar Thermal Electrochemical Photo (STEP) Carbon Capture. Phys. Chem. Lett 2010; 1 (15) : 2363-2368. doi:10.1021/jz100829s

[35] S. Licht. Efficient Solar - Driven Synthesis, Carbon Capture, and Desalinization, STEP: Solar Thermal Electrochemical Production of Fuels, Metals, Bleach. Adv. Mater 2011; 23 : 5592-5612. doi:10.1002/adma.201103198

[36] K. Simmons, J.S. Martin, I. Shcherbakova, et al. Chapter 3 - Rapid Quantification and Analysis of Kinetic • OH Radical Footprinting Data Using SAFA. Methods in Enzymology 2009; 468 : 47-66. doi:10.1016/S0076-6879(09)68003-4

[37] C.A. Martinez-Huitle, S. Ferro. Electrochemical oxidation of organic pollutants for the wastewater treatment: direct and indirect processes. Chem. Soc. Rev 2006; 35 : 1324-1340. doi:10.1002/chin.200714276

[38] X. Luo, L. Ghassemzadeh, S. Holdcroft. Effect of free radical-induced degradation on water permeation through PFSA ionomer membranes. International Journal of Hydrogen Energy 2015; 40 : 16714-16723. doi:10.1016/j.ijhydene.2015.07.118

[39] L. An, T.S. Zhao, Z.H. Chai, et al. Mathematical modeling of an anion-exchange membrane water electrolyzer for hydrogen production. International Journal of Hydrogen Energy 2014; 39 : 19869-19876. doi:10.1016/j.ijhydene.2014.10.025 


\section{Figure captions}

Scheme 1 Schematic logo of STEP organic decomposition

Scheme 2 Schematic diagram of the STEP organic decomposition

Fig. 1 Thermodynamic calculation of temperature variation of acrylonitrile oxidation potential

Fig. 2 High-temperature cyclic voltammogram of aqueous acrylonitrile(200 ppm in $\left.5 \mathrm{~g} / \mathrm{L} \mathrm{Na}_{2} \mathrm{SO}_{4}\right)$ at different temperatures measured indoors at a constant temperature at a sweep rate of $100 \mathrm{mV} / \mathrm{s}$ using a three electrode configuration with $8 \mathrm{~cm}^{2}$ working and counter electrodes and a saturated calomel reference electrode (Insert: Anodic oxidation peak variation with temperature)

Fig. 3 Temperature variation of anodic oxidation peak potential and current (A-II)

Fig. 4 Variation with temperature of the anodic (top, $\mathrm{O}_{2}$ formation) and cathodic (bottom, $\mathrm{H}_{2}$ formation) potential of water electrolysis

Fig. 5 Dependence of temperature and applied potential as a function of time at a constant current (50 mA) in the outdoor experiment; 200 ppm in $5 \mathrm{~g} / \mathrm{L} \mathrm{Na}_{2} \mathrm{SO}_{4}$

Fig. 6 Dependence of decomposition rate of acrylonitrile (200 ppm in 5g/L Na $2 \mathrm{SO}_{4}$ ) at fixed electrolysis current (50 mA) and time interval for $1 \mathrm{~h}$

Fig. 7 Temperature variations of the STEP acrylonitrile decomposition kinetics rate; electrolysis current: $50 \mathrm{~mA}$, time: $1 \mathrm{~h}$, concentration: $200 \mathrm{ppm}$ in $5 \mathrm{~g} / \mathrm{L} \mathrm{Na}_{2} \mathrm{SO}_{4}$

Fig. 8 Gas chromatogram of the initial reactants and intermediates in the solar STEP acrylonitrile decomposition (1000 ppm in $10 \mathrm{~g} / \mathrm{L} \mathrm{Na} \mathrm{SO}_{4}$ ) at $25^{\circ} \mathrm{C}$ and $75^{\circ} \mathrm{C}$ for $5 \mathrm{~h}$

Fig. 9 Concentration variation of the initial reactant (acrylonitrile) and intermediate (acetonitrile) in the two modes (blue, $25^{\circ} \mathrm{C} ;$ red, $\left.75^{\circ} \mathrm{C}\right)$

Scheme 3 Schematic mechanisms and pathways of the thermo- and electrochemical decomposition of acrylonitrile 


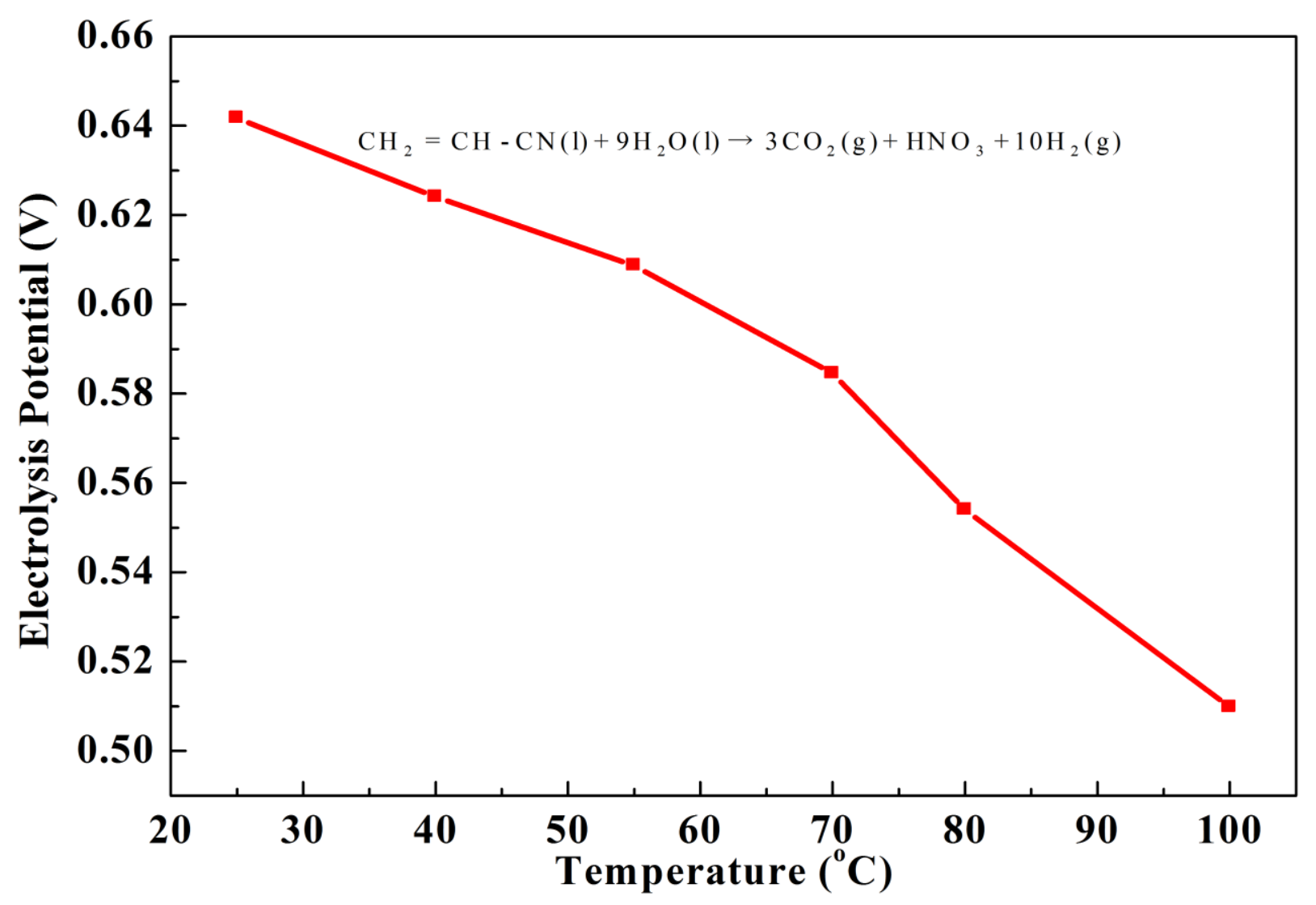




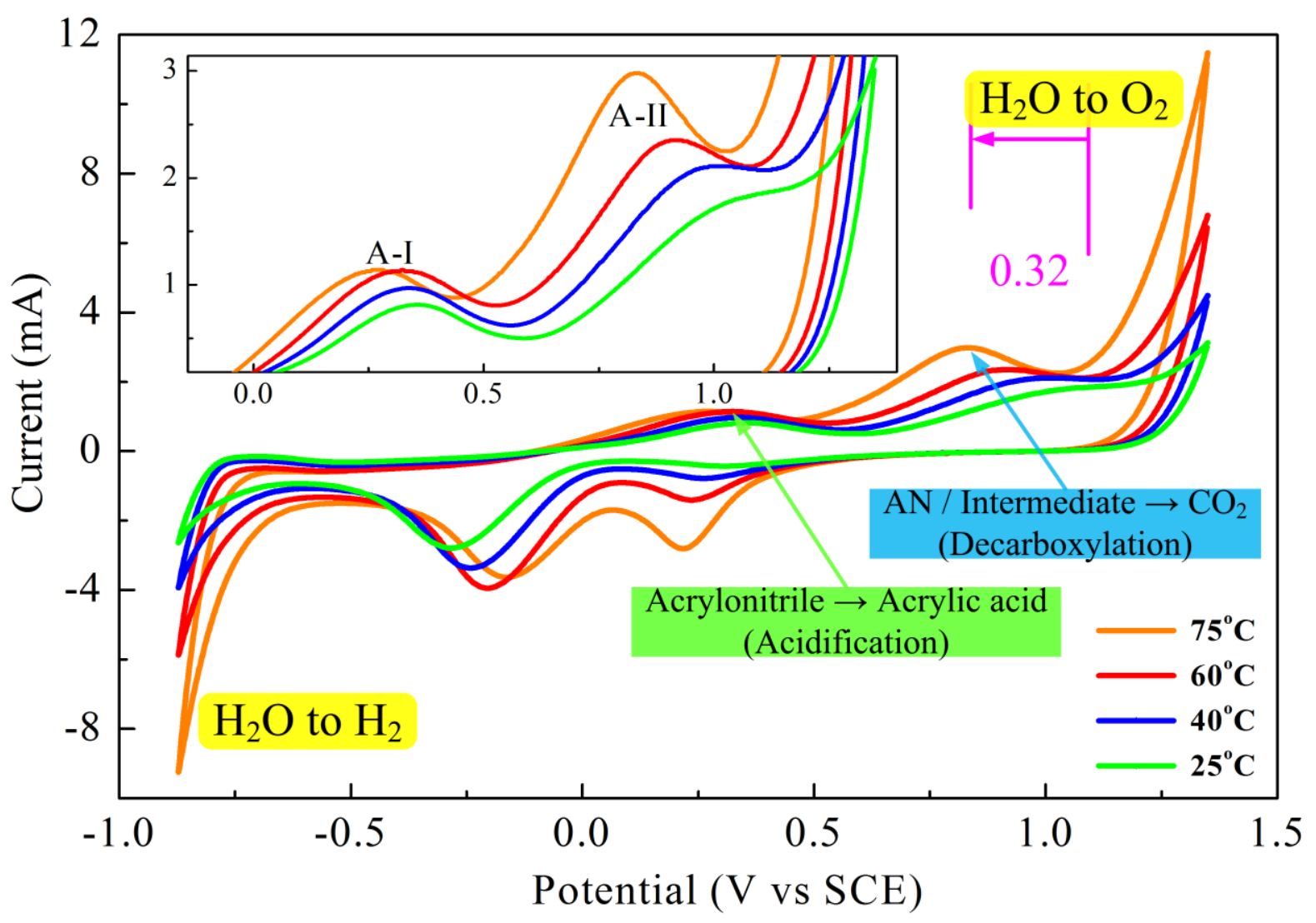




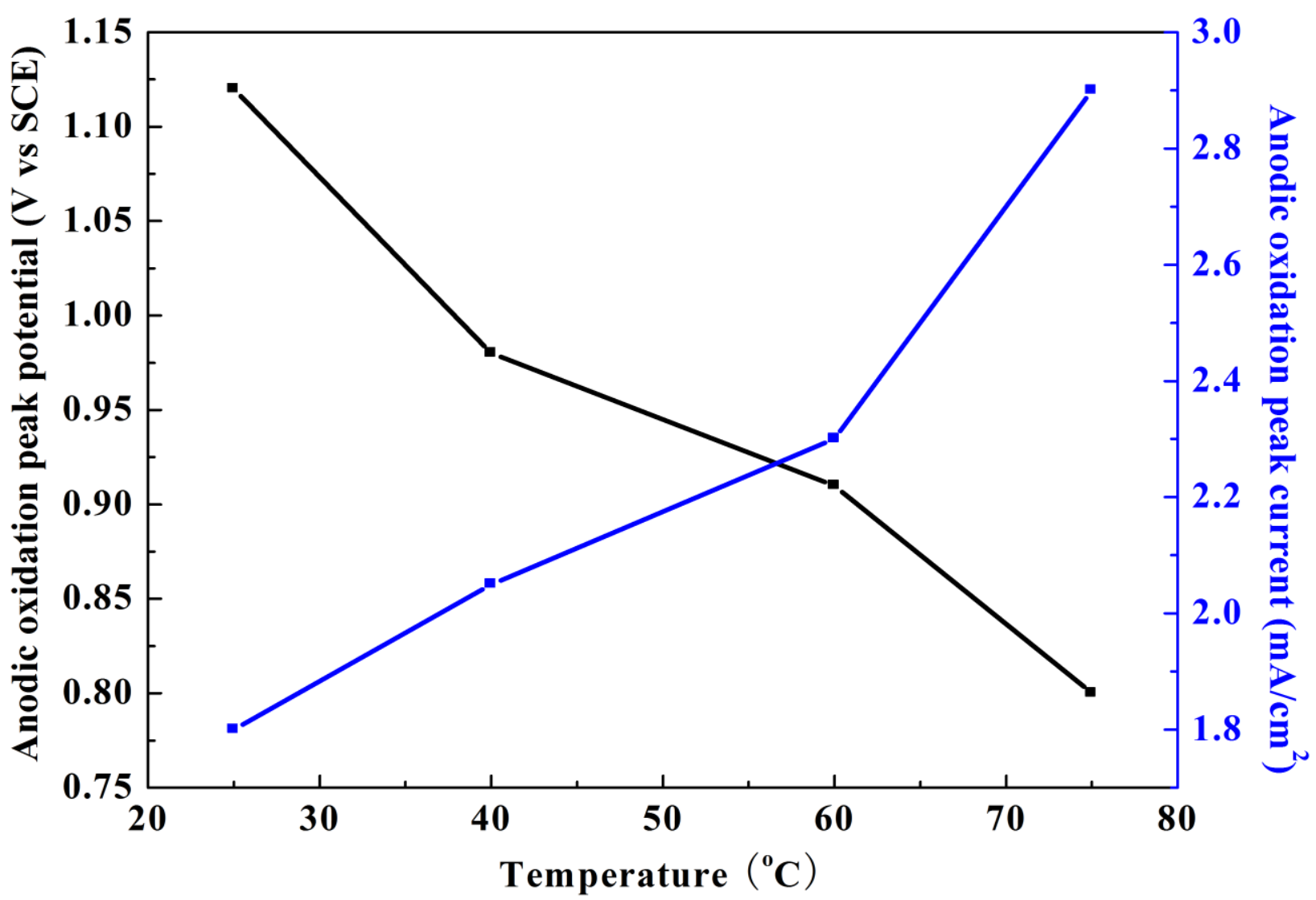




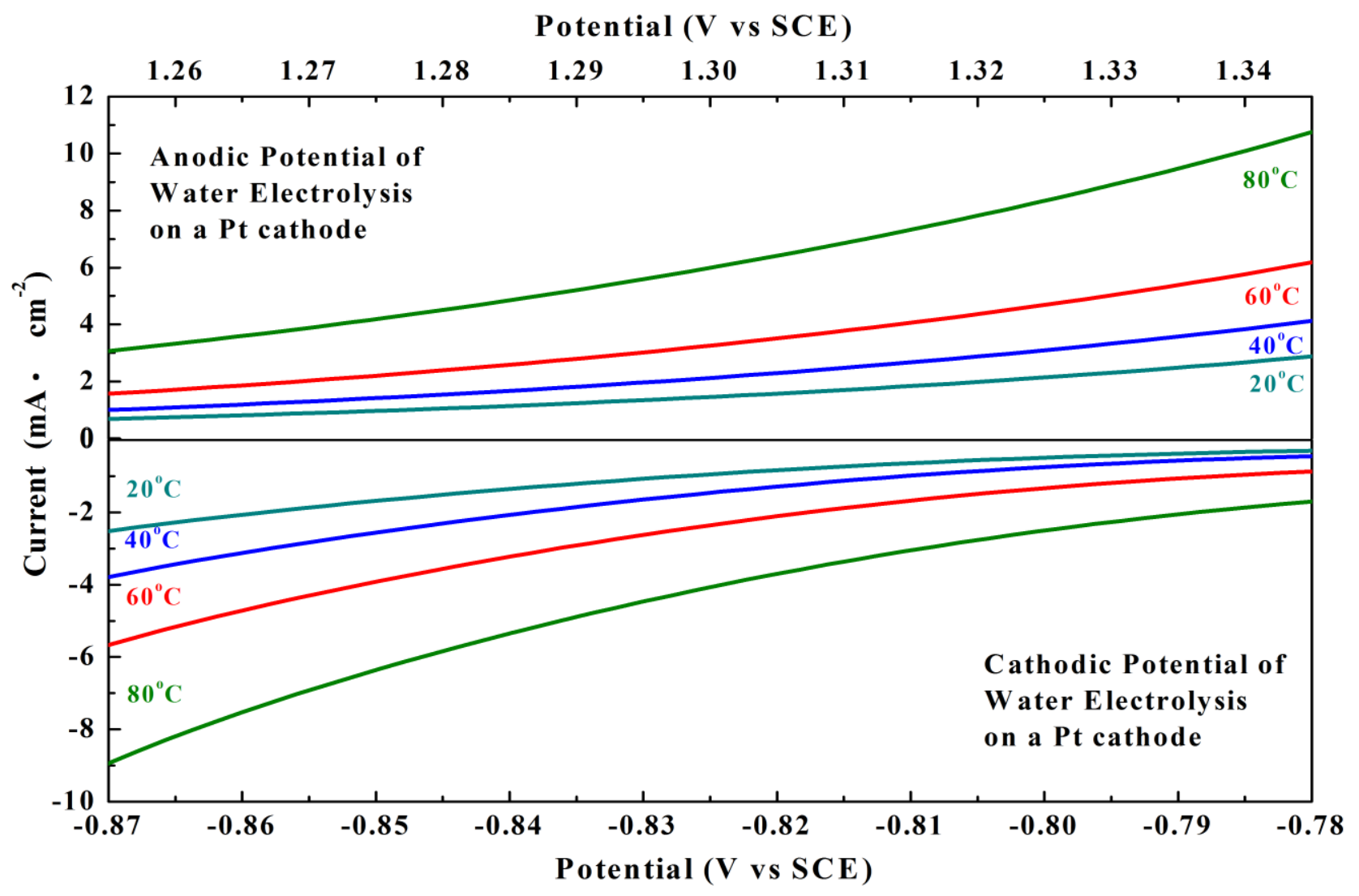




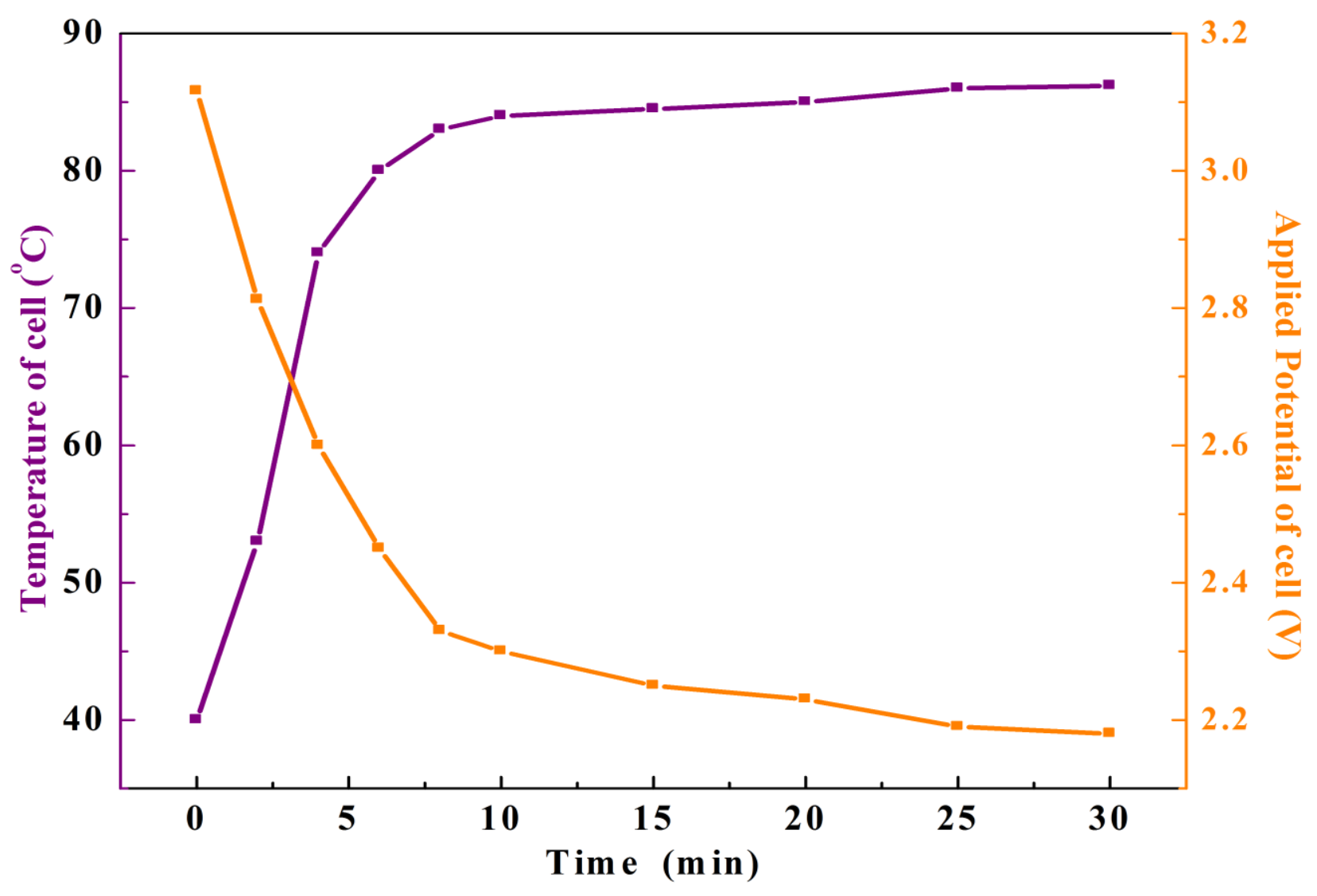




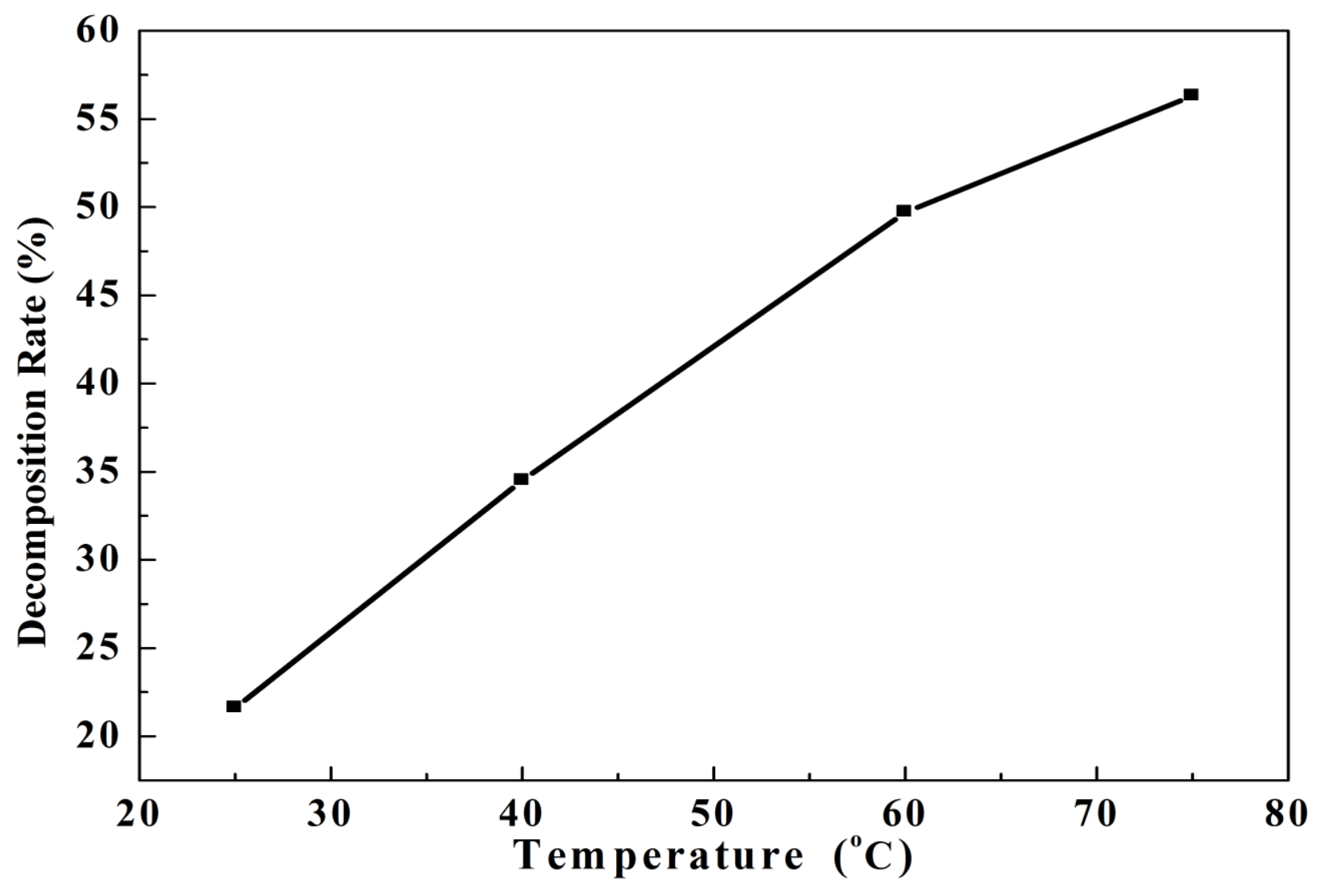




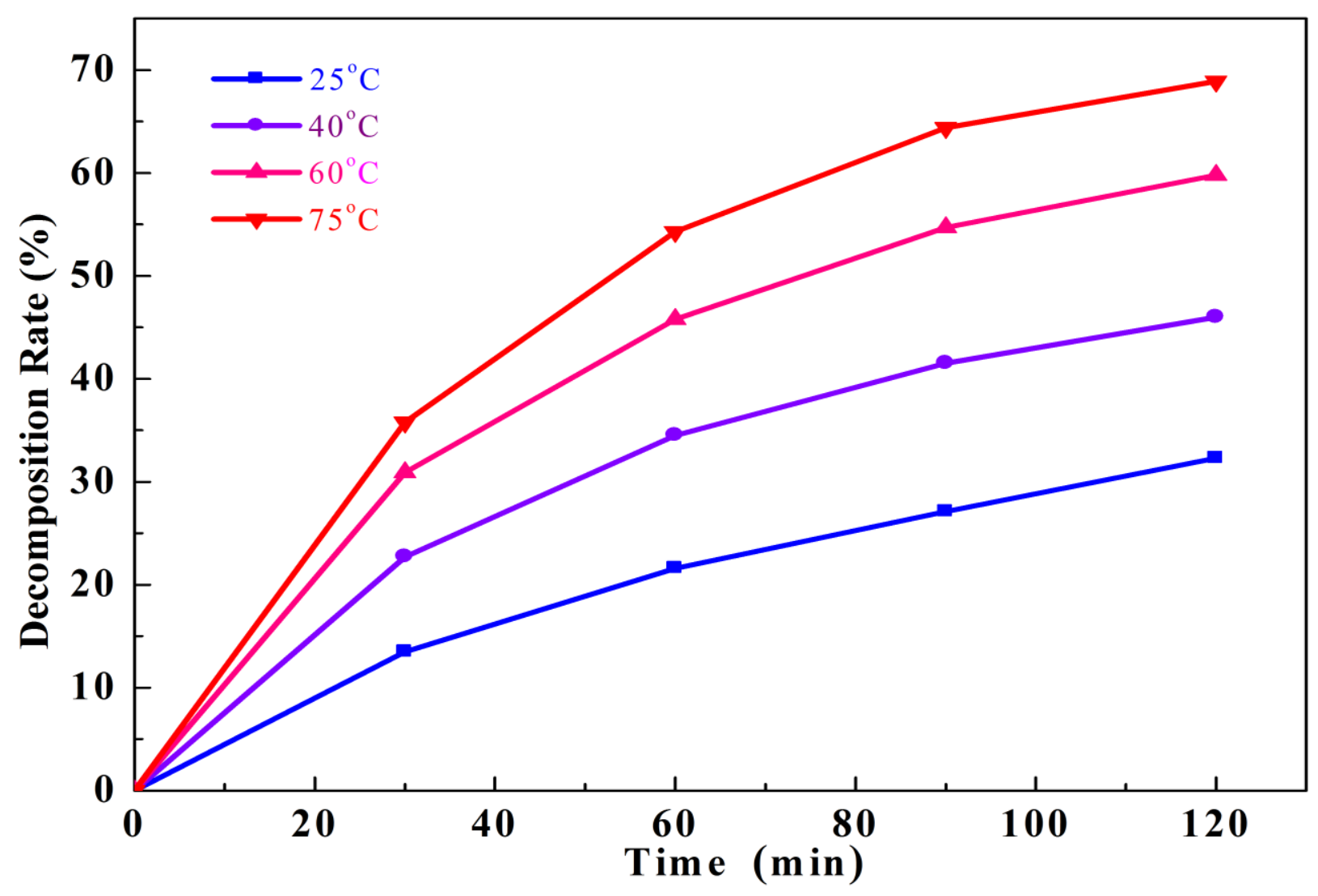




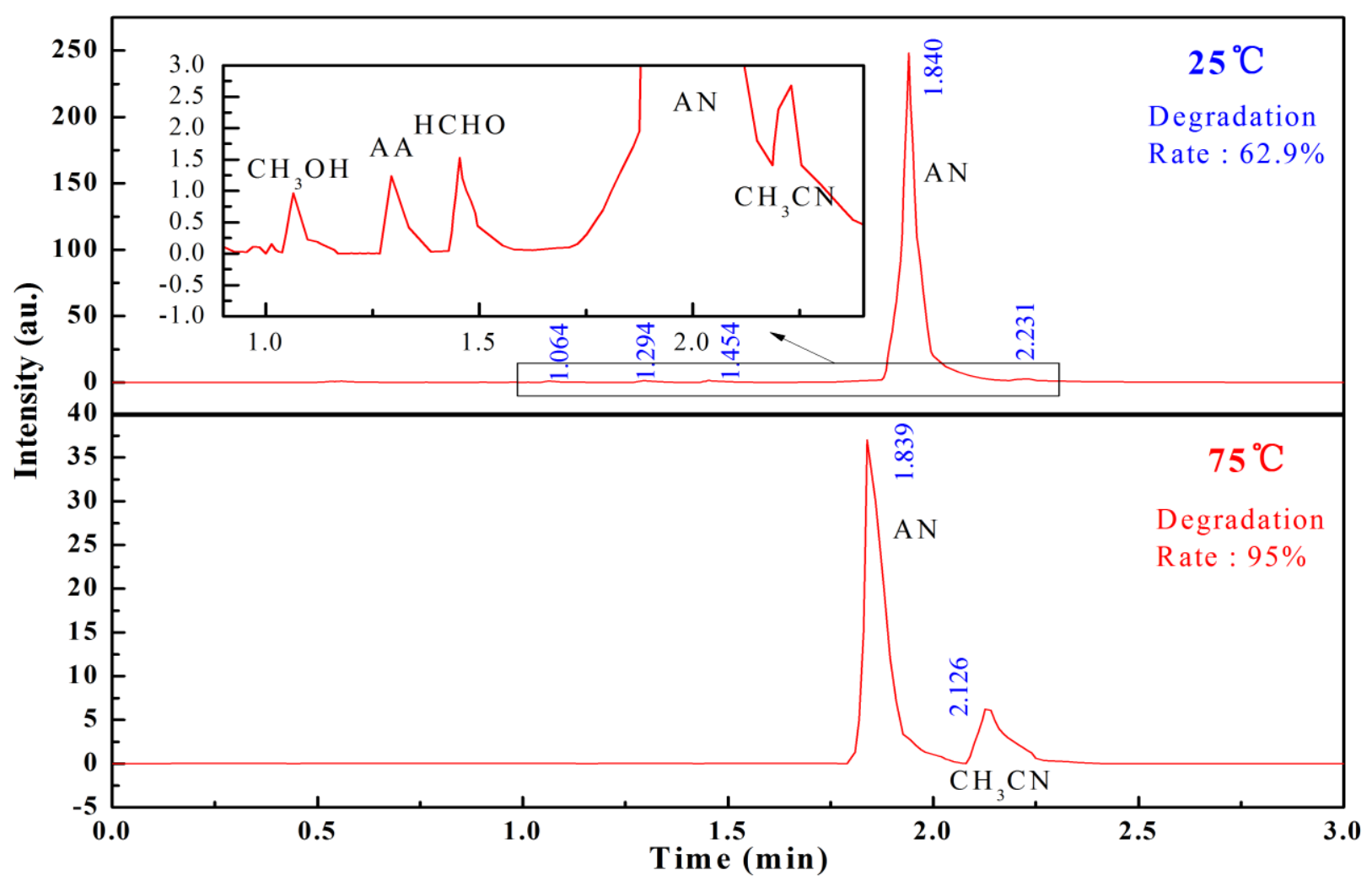




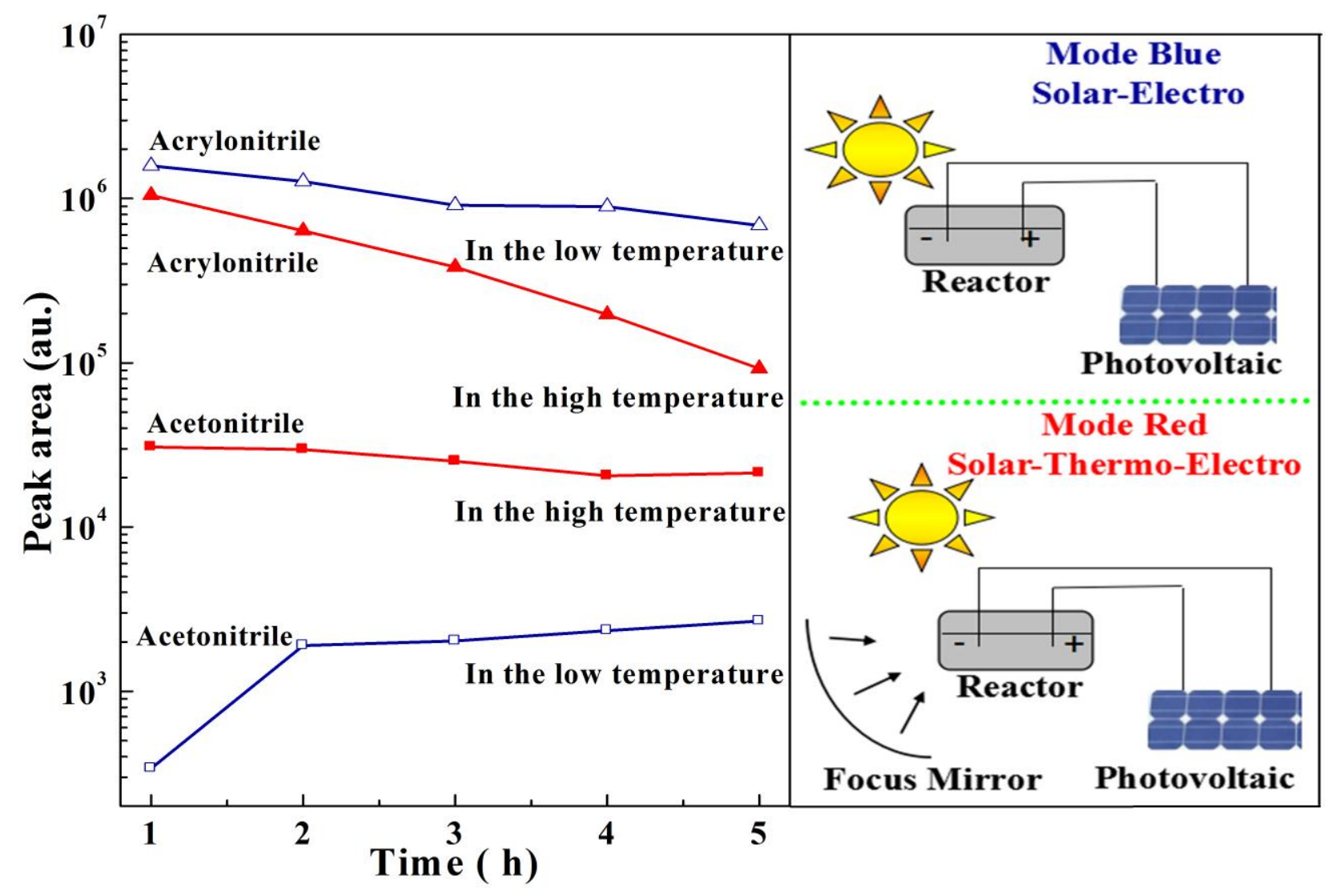




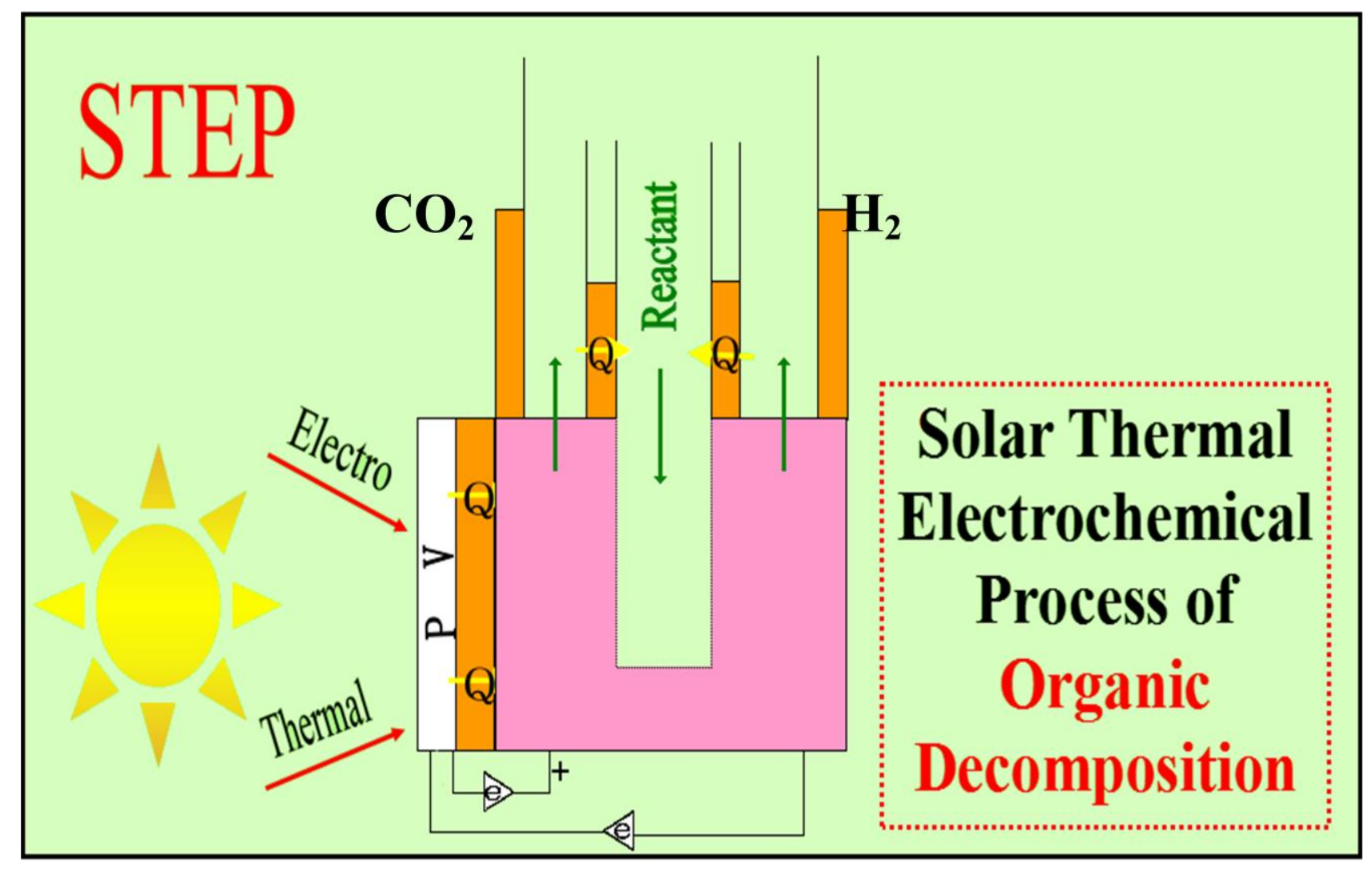




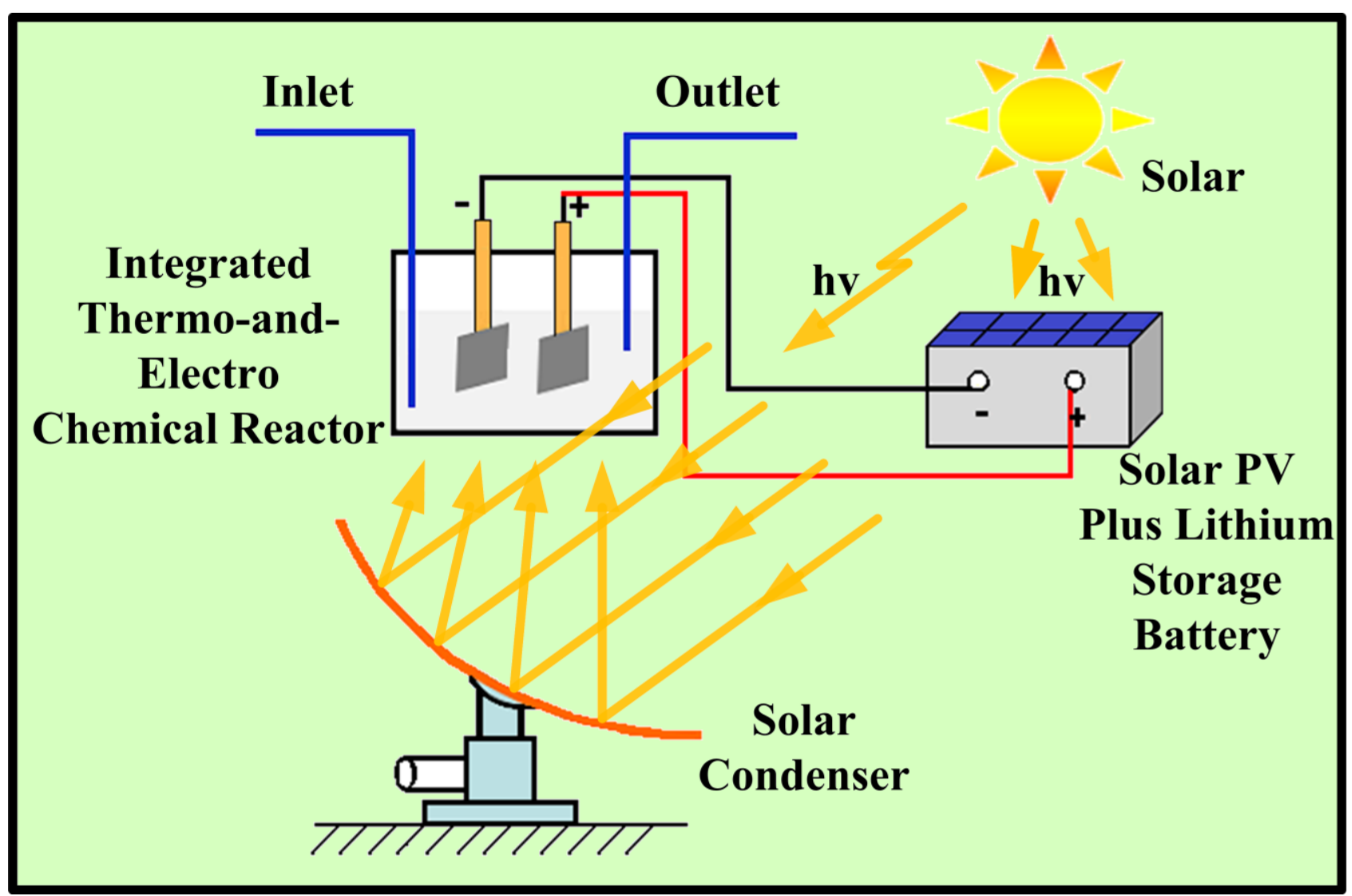




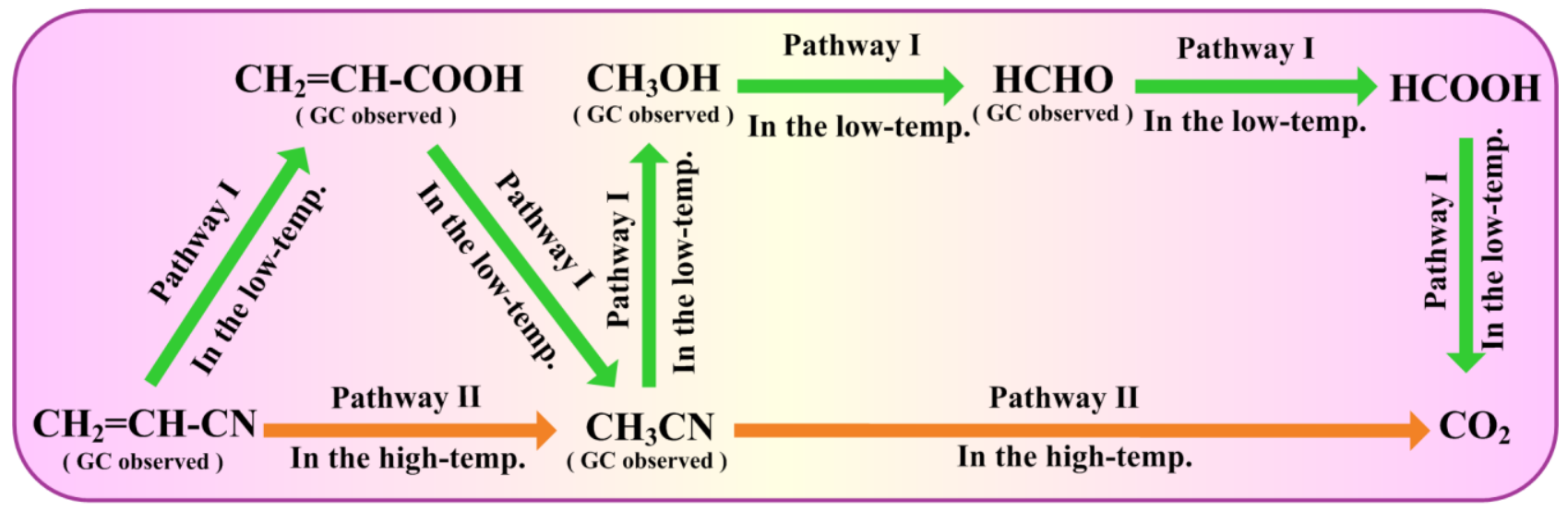




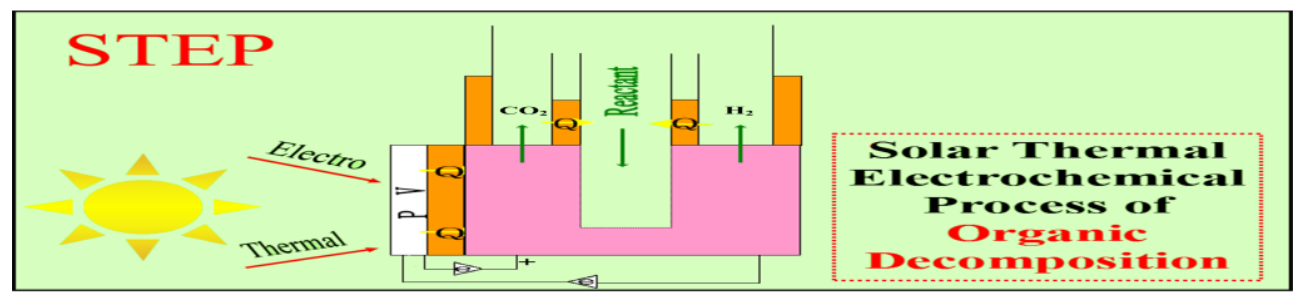

